\title{
Extruded sorghum consumption associated with a caloric restricted diet reduces body fat in overweight men: A randomized controlled trial
}

\author{
Pamella Cristine Anunciação ${ }^{\mathrm{a}, *}$, Leandro de Morais Cardoso ${ }^{\mathrm{b}}$, Rita de Cássia Gonçalves Alfenas ${ }^{\mathrm{a}}$, \\ Valéria Aparecida Vieira Queiroz ${ }^{\mathrm{c}}$, Carlos Wanderlei Piler Carvalho ${ }^{\mathrm{d}}$, \\ Hércia Stampini Duarte Martino ${ }^{a}$, Helena Maria Pinheiro-Sant'Ana ${ }^{a}$ \\ ${ }^{a}$ Departamento de Nutrição e Saúde, Universidade Federal de Viçosa, Viçosa, Minas Gerais, Brazil \\ b Departamento de Nutrição, Universidade Federal de Juiz de Fora, Campus Governador Valadares, Governador Valadares, Minas Gerais, Brazil \\ ${ }^{\mathrm{c}}$ EMBRAPA Milho e Sorgo, Sete Lagoas, Minas Gerais, Brazil \\ d EMBRAPA Agroindústria de Alimentos, Rio de Janeiro, Brazil
}

\section{A R T I C L E I N F O}

\section{Keywords:}

Sorghum bicolor L.

Body composition

Obesity

Bioactive compounds

Dietary fiber

Whole grains

\begin{abstract}
A B S T R A C T
This study aimed to evaluate the effect of sorghum intake on body composition and metabolic variables in overweight men. In a randomized controlled crossover study, 24 overweight men $(25.6 \pm 4.6$ years $)$ were randomly allocated into one of two treatments: extruded sorghum or extruded wheat. The study consisted of 2 periods of 8 weeks with at least 4 weeks of washout. Anthropometric, clinical and metabolic risk variables were assessed at baseline and at the end of each intervention period. Extruded sorghum consumption reduced body fat percentage and increased daily carbohydrate and dietary fiber intake when compared to wheat consumption. Also, sorghum increased the serum glutathione peroxidase concentration, but no difference was observed when compared to wheat consumption. Extruded sorghum demonstrated to be a good alternative to control obesity in overweight men.
\end{abstract}

\section{Introduction}

Obesity is a worldwide public health problem because of its high prevalence. $>1.9$ billion adults were overweight and over 600 million were obese in 2014 (World Health Organization, 2016). The excessive accumulation of visceral fat is related with low-grade inflammation and oxidative stress (Matsuda \& Shimomura, 2013). Oxidative stress, an imbalance between the generation of free radical such as reactive oxygen/nitrogen species and the antioxidant defenses, is associated with the manifestation of obesity, diabetes and cardiovascular diseases (Khan, Yousif, Johnson, \& Gamlath, 2015; Lee, Han, Song, \& Yeum, 2015). Free radicals may react with some biomolecules, including lipids, carbohydrates, proteins, and nucleic acids, thereby interfering with cell function (Erciyas, Taneli, Arslan, \& Uslu, 2004). Our cells are protected against the harmful effects of reactive oxygen species by antioxidant enzymes (e.g., superoxide dismutase, glutathione peroxidase and catalase) and other antioxidant substances (e.g., vitamin C, vitamin E, vitamin A, carotenoids and glutathione) (Matsuda \&
Shimomura, 2013).

Dietary restriction represents the most conventional treatment for overweight and obesity (World Health Organization, 2000). Consumption of whole grains contributes to reducing the risks of obesityrelated comorbidities (Farrar, Hartle, Hargrove, \& Greenspan, 2008). Phytochemicals present in cereals, such as phenolic compounds, act to protect the body against oxidative stress and its effects, due to its antioxidant properties (Taylor, Belton, Beta, \& Duodu, 2014). Among these cereals, sorghum has stood out because its higher phytochemical content compared to wheat (Anunciação et al., 2017), one of the major cereals produced and consumed in Brazil. Our group has previously conducted sorghum (Sorghum bicolor L.) characterization studies (Anunciação et al., 2017; Cardoso et al., 2015a; Cardoso et al., 2015b; Lopes et al., 2018) and verified that sorghum, especially the SC319 genotype, stands out as an excellent source of bioactive compounds including flavonoids, tannins, anthocyanins, vitamin $\mathrm{E}$ and carotenoids, which contribute to its high antioxidant capacity. Whole-grain wheat breakfast cereal is also a good source of vitamin E and phenolic

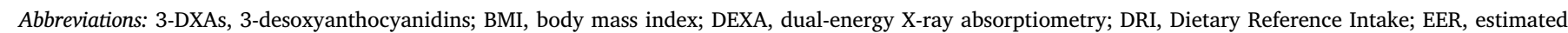

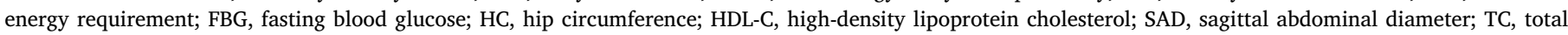
cholesterol; TG, triglycerides; WC, waist circumference; WHR, waist-to-hip ratio; WHtR, waist-to-height ratio

* Corresponding author.

E-mail addresses: nutripamella@gmail.com, pamella.anunciacao@ufv.br (P.C. Anunciação). 
Table 1

Nutrient and bioactive compounds content in test meals.

\begin{tabular}{|c|c|c|c|c|c|c|}
\hline Preparations & $\begin{array}{l}\text { Sorghum breakfast } \\
\text { cereal }+ \text { milk }\end{array}$ & $\begin{array}{l}\text { Wheat breakfast } \\
\text { cereal }+ \text { milk }\end{array}$ & $\begin{array}{l}\text { Sorghum breakfast } \\
\text { cereal }+ \text { yoghurt }\end{array}$ & $\begin{array}{l}\text { Wheat breakfast } \\
\text { cereal + yoghurt }\end{array}$ & $\begin{array}{l}\text { Sorghum } \\
\text { drink }\end{array}$ & $\begin{array}{l}\text { Wheat } \\
\text { drink }\end{array}$ \\
\hline \multicolumn{7}{|l|}{ Ingredients ( $\mathrm{g} /$ serving $)^{1}$} \\
\hline Extruded sorghum (g) & 40 & - & 40 & - & 40 & - \\
\hline Extruded wheat (g) & - & 38 & - & 38 & - & 38 \\
\hline Milk (mL) & 100 & 100 & - & - & - & - \\
\hline Yoghurt (mL) & - & - & 185 & 185 & - & - \\
\hline Powdered skim milk (g) & - & - & - & - & 25 & 25 \\
\hline Powdered drink (g) & - & - & - & - & 2 & 2 \\
\hline Sweetener (mL) & - & - & - & - & 0.05 & 0.05 \\
\hline \multicolumn{7}{|l|}{ Chemical composition } \\
\hline Energy $(\mathrm{Kcal})^{2}$ & 176.39 & 177.73 & 194.65 & 195.99 & 223.59 & 224.93 \\
\hline Total carbohydrates $(\mathrm{g})^{2}$ & 34.94 & 36.16 & 37.34 & 38.56 & 41.94 & 43.16 \\
\hline Protein $(\mathrm{g})^{2}$ & 7.63 & 7.76 & 9.80 & 9.93 & 12.43 & 12.56 \\
\hline Fat $(g)^{2}$ & 0.68 & 0.23 & 0.68 & 0.23 & 0.68 & 0.23 \\
\hline Total dietary fiber $(\mathrm{g})^{2}$ & 5.84 & 4.56 & 5.84 & 4.56 & 5.84 & 4.56 \\
\hline Soluble fiber $(\mathrm{g})^{2}$ & 0.46 & nd & 0.46 & nd & 0.46 & nd \\
\hline Insoluble fiber $(\mathrm{g})^{2}$ & 5.37 & nd & 5.37 & nd & 5.37 & nd \\
\hline Resistant starch (g) & 1.18 & nd & 1.18 & nd & 1.18 & nd \\
\hline Total phenolic (mg GAE/g) & 1.15 & 0.12 & 1.08 & 0.11 & 1.07 & 0.03 \\
\hline 3-DXAs $(\mu \mathrm{g} / \mathrm{g})$ & 7.64 & 0 & 4.71 & 0 & 4.20 & 0 \\
\hline $\begin{array}{l}\text { Proanthocyanidins ( } \mu \mathrm{g} \text { Cat } \\
\text { Eq.) }\end{array}$ & 0.40 & nd & 0.40 & nd & 0.40 & nd \\
\hline
\end{tabular}

1 Daily serving of sorghum breakfast cereal = $40 \mathrm{~g}$; wheat breakfast cereal = 38 g; drinks $=250$ mL. 3-DXAs: 3-desoxyanthocyanidins; nd: not determined.

2 Based on information obtained on the label of ingredients used to prepare the test meals.

compounds, contributing to its antioxidant capacity (Anunciação et al., 2017).

There is now an increased interest in using sorghum in human nutrition since is gluten-free (Pontieri et al., 2013) and is safe for celiac patients (Ciacci et al., 2007) and due to other properties, such as slow digestibility, cholesterol lowering, anti-inflammatory, anti-diabetes and anti-cancer properties (Anunciação et al., 2018; Dykes \& Rooney, 2006; Lopes et al., 2018; Moraes et al., 2012; Yang, Browning, \& Awika, 2009). Additionally, our previous study demonstrated that extruded sorghum (as breakfast cereal) has good acceptance and is a source of bioactive compounds (Anunciação et al., 2017). Extrusion is an industrial cooking process that combines high pressure, heat and mechanical force in a short period of time, causing physical and chemical changes to the food matrix (Chávez, Ascheri, Carvalho, Godoy, \& Pacheco, 2017). Expanded extrudes, such as snacks or breakfast cereal, are very popular due to the fact that they are easy to consume. Furthermore, extruded sorghum flour may be indicated for use in ready-toeat porridge or even for the preparation of drinks (Anunciação et al., 2018).

Consumption of foods containing sorghum flour as an ingredient has the potential to enhanced antioxidant status and beneficially modulate oxidative stress markers in humans (Khan et al., 2015; Lopes et al., 2018). The activity of components isolated from sorghum against oxidative stress has been demonstrated in vitro (Yang et al., 2009) and in vivo (Moraes et al., 2018). In addition, we identified one study that evaluated the acute effect of sorghum flour on oxidative stress markers in healthy subjects (Khan et al., 2015). A study using the same sorghum genotype verified that its consumption reduced the metabolic risk of obesity associated with adiposity and inflammation in obese rats (Arbex et al., 2018). These functional benefits are attributed to the phenolic compounds of sorghum (Khan et al., 2015). However, studies about the effect of chronic consumption of sorghum-based preparations on weight loss and markers of oxidative stress in overweight humans are lacking. We hypothesized that extruded sorghum consumption could reduce the metabolic risk of obesity associated with adiposity in humans.

Thus, the present study aimed to evaluate the effect of sorghum intake on body composition, serum levels of lipids and glucose, and oxidative stress markers in overweight men during a weight loss nutritional intervention.

\section{Methods}

\subsection{Subjects}

Study participants were recruited through public advertisements. Eligibility criteria included: male; age 18-40 years; body mass index (BMI) $27.0-34.9 \mathrm{~kg} / \mathrm{m}^{2}$; waist circumference $\geq 90 \mathrm{~cm}$; fasting capillary blood glucose 70-99 mg/dL; capillary cholesterol $<240 \mathrm{mg} / \mathrm{dL}$; capillary triglycerides $<150 \mathrm{mg} / \mathrm{dL}$; absence of food allergies, acute and chronic diseases other than obesity. We included only men, since they do not present hormonal changes as occur with women in the menstrual period.

Individuals with acute diseases and/or eating disorders (lactose or gluten intolerances) were not included. Other exclusion criteria were the use of medications known to affect appetite, glycaemia, and energy or lipid metabolism; alcohol consumers and/or smokers; use of dietary fiber supplement; recent changes in body weight $(<5 \mathrm{~kg}$ in the past three months); no consumption of the test food for more than six days, consecutive or no.

The study was approved by the Human Research Ethics Committee of the Federal University of Viçosa, Brazil (CAAE: 13630513.0.0000.5153). All volunteers were informed about the objectives of the study and provided written informed consent. The study presented a power (Mera, Thompson, \& Prasad, 1998) of $80 \%$ to lead to a $7.5 \%$ body fat reduction $(\alpha=0.05, \mathrm{SD}=5.25)$.

\subsection{Study design}

This is a randomized controlled crossover $2 \times 2$, single blind, clinical trial. Twenty-four subjects were randomly allocated into one of two treatments, when extruded sorghum-based preparations $(40 \mathrm{~g} / \mathrm{d})$ or extruded wheat-based preparations $(38 \mathrm{~g} / \mathrm{d})$ were consumed for breakfast for eight consecutive weeks. We used wheat as a control meal since it is highly consumed by Brazilian population. In addition, the whole-grain wheat is also rich in dietary fiber, vitamins and phenolic compounds as described in Table 1. A 4-week washout period was incorporated between treatments in order to eliminate residuals effects (carryover) of the first period.

Subjects consumed the test preparations (breakfast cereal or a 
drink) at breakfast daily in the laboratory. On weekends, the preparations were provided to volunteers to be ingested in their own homes. For that, subjects received portions of each test preparation and a measuring cup indicating the exact amount of water or milk to be added ( $250 \mathrm{~mL}$ or $100 \mathrm{~mL}$, respectively) to ensure appropriate dilution. The volunteers were instructed to consume the entire amount of test food provided.

Energy restriction (500 kcal/day) was based on the estimated energy requirement (EER) (Institute of Medicine, 2005), presuming an individual weight loss of $2 \mathrm{~kg} / \mathrm{month}$. The dietary intervention for both groups was conducted by nutritionists, and dietary prescription was based on Dietary Reference Intakes (DRIs) (Institute of Medicine, 2005), considering the nutritional composition of the test preparations provided during the study. Nutrient composition was calculated using the Avanutri software (version 5.5i, Brazil) or considering food labels information. Subjects received a replacement foods list organized by food groups and guidelines regarding healthy food choices. They were asked to maintain their customary physical activity level.

\subsection{Test meal}

The test meal was a breakfast cereal or a drink. Sorghum (test meal) or wheat (control meal) breakfast cereals (Anunciação et al., 2017) were served with milk $(100 \mathrm{~mL})$ or yoghurt $(185 \mathrm{~mL})$. All volunteers consumed milk or yoghurt for the same number of times. The drink was prepared just before its consumption and consisted of water, extruded sorghum or wheat flour, milk powder, powdered drink (Clight ${ }^{\circledast}$, two flavors: blackberry or peach) and sweetener (sucralose). These preparations had similar calories, macronutrients and dietary fiber content (Table 1).

The amount of sorghum consumed daily was based on a usual portion of breakfast cereal $(40 \mathrm{~g})$ and on the volume of sorghum that the subjects could ingest in a meal based on previous tests. The amount of wheat was calculated to keep the same amount of milk or yoghurt that was provided with the sorghum portion, and provide similar concentration of calories, macronutrient and dietary fiber with the sorghum.

\subsection{Dietary intake assessment}

Before and after each intervention period, participants provided a 3day food record (two nonconsecutive week days and one weekend day). Each food record was reviewed with the participants to ensure accuracy and completeness. Moreover, a food portion photo album was used to define the size of the portions ingested and to improve data quality (Monteiro, 2007). The portion sizes of the food intake were converted into grams. Total calories, carbohydrates, lipids, proteins and dietary fiber consumed were analyzed using Avanutri software (version 5.5i, Brazil).

\subsection{Anthropometric and body composition measurements}

Anthropometric and body composition evaluations were performed by a single trained researcher. Body weight was assessed using an electronic platform scale (Model 2096 PP, Toledo Brazil), with a capacity for $150 \mathrm{~kg}$ and precision of $50 \mathrm{~g}$. Height was measured using a stadiometer (Alturexata ${ }^{\circledR}$, Brazil) fixed to the wall (Jellife, 1966). BMI $\left(\mathrm{kg} / \mathrm{m}^{2}\right)$ was computed and classified according to WHO (2000).

Waist circumference (WC) was measured to the nearest $0.1 \mathrm{~cm}$ with a flexible band, at the midpoint between the last rib and the iliac crest (World Health Organization, 2000). WC $\geq 90 \mathrm{~cm}$ was adopted as a criterion to diagnose abdominal obesity. Hip circumference (HC) was measured with inelastic tape measure at the level of maximum protrusion of the gluteal muscles. Sagittal abdominal diameter (SAD) was measured with a portable, sliding beam, abdominal caliper (Holtain Kahn Abdominal Caliper ${ }^{\circledast}$, Holtain Ltd., Dyfed, Wales, UK) at the midpoint between the iliac crests. Waist-to-hip ratio (WHR) was calculated as WC divided by HC and waist-to-height ratio (WHtR) as WC divided by height.

Body composition was assessed by dual-energy X-ray absorptiometry (DEXA) (GE Healthcare, Lunar Prodigy Advance), and the results were expressed as total body fat (\%). Obesity was identified when body fat \% was higher than 25\% (Sociedad Espanola para el Estudio de la Obesidad, 2000).

\subsection{Clinical assessments}

Blood pressure was assessed as recommended by the American Heart Association (AHA) (Pickering et al., 2005).

Overnight fasting blood samples were collected from all of the volunteers at the beginning and the end (after 8 weeks) of each intervention period. Fasting blood glucose (FBG), total cholesterol (TC), high-density lipoprotein cholesterol (HDL-c) and triglycerides (TG) were measured using enzymatic kits and colorimetric methods (glucose monoreagent, monoreagent cholesterol, triglycerides and HDL Direct monoreagent from Bioclin ${ }^{\circledR}$, Brazil). Low-density lipoprotein cholesterol (LDL-c) levels were estimated in accordance with the Friedewald formula (Friedewald, Levy, \& Fredrickson, 1972). Fasting insulin was assessed by electrochemiluminescence and high-sensitivity C-reactive protein (hs-CRP), by nephelometry.

Serum retinol, carotenoids ( $\alpha$-carotene, $\beta$-carotene and lutein) and tocopherols ( $\alpha$ - and $\gamma$-tocopherols) were assessed according to Turner and Burri (2012) with modifications. The vitamins were determined in a high performance liquid chromatography (HPLC) system (Shimadzu, SCL 10AT VP, Japan) equipped with diode array detector (Shimadzu, SPD-M10A, Japan), high pressure pump (Shimadzu, LC-10AT VP, Japan), autosampler with loop of $500 \mu \mathrm{L}$ (Shimadzu, SIL-10AF, Japan), and helium degassing system. The following chromatographic conditions were used: RP-18 column (Phenomenex Gemini, $250 \mathrm{~mm} \times 4.6 \mathrm{~mm}, 5 \mu \mathrm{m}$ ), equipped with a C-18 guard column (Phenomenex ODS $4 \mathrm{~mm} \times 3 \mathrm{~mm}$ ). The injection volume was $40 \mu \mathrm{L}$ and spectrum scan was $200-450 \mathrm{~nm}$. Retinol, carotenoids and tocopherols were measured at 325,450 and $292 \mathrm{~nm}$, respectively. The mobile phase was composed of acetonitrile: dichloromethane: methanol (70:20:10) and flow rate was $1.0 \mathrm{~mL} / \mathrm{min}$.

Total antioxidant capacity was measured using the Antioxidant Assay Kit (Sigma $\left.{ }^{\circledast}\right)$. Glutathione peroxidase (GPx) was measured by colorimetric method using a kit EGPX-100 (EnzyChrom).

\subsection{Statistical analysis}

Statistical analysis was performed using SPSS 20.0 software. The normality of the data was assessed by Shapiro-Wilk test. The average of each variable at the beginning and end of the intervention were compared using paired $t$-test or Wilcoxon. The difference between the averages of the variables at the beginning and end of the intervention periods were compared using the Student $t$-test or Mann Whitney. The difference between the average food intake, within the same treatment, was evaluated using the Student $t$-test or Mann-Whitney test. A significance level $(\alpha)$ of $5 \%$ was adopted. The graphs were made using the software GraphPad Prism, version 5.0 (GraphPad Software, San Diego, CA).

\section{Results}

Thirty-six overweight men (19-39 years of age) completed the first screening visit. However, 33 attended the initial assessments and 24 participants completed the study (Fig. 1). The average age of participants was $25.6 \pm 4.6$ years. Their general characteristics are reported in Table 2. The participants did not present differences in the anthropometric, biochemical and food consumption parameters in the baseline (Table 2), except for dietary fiber consumption, which was higher 


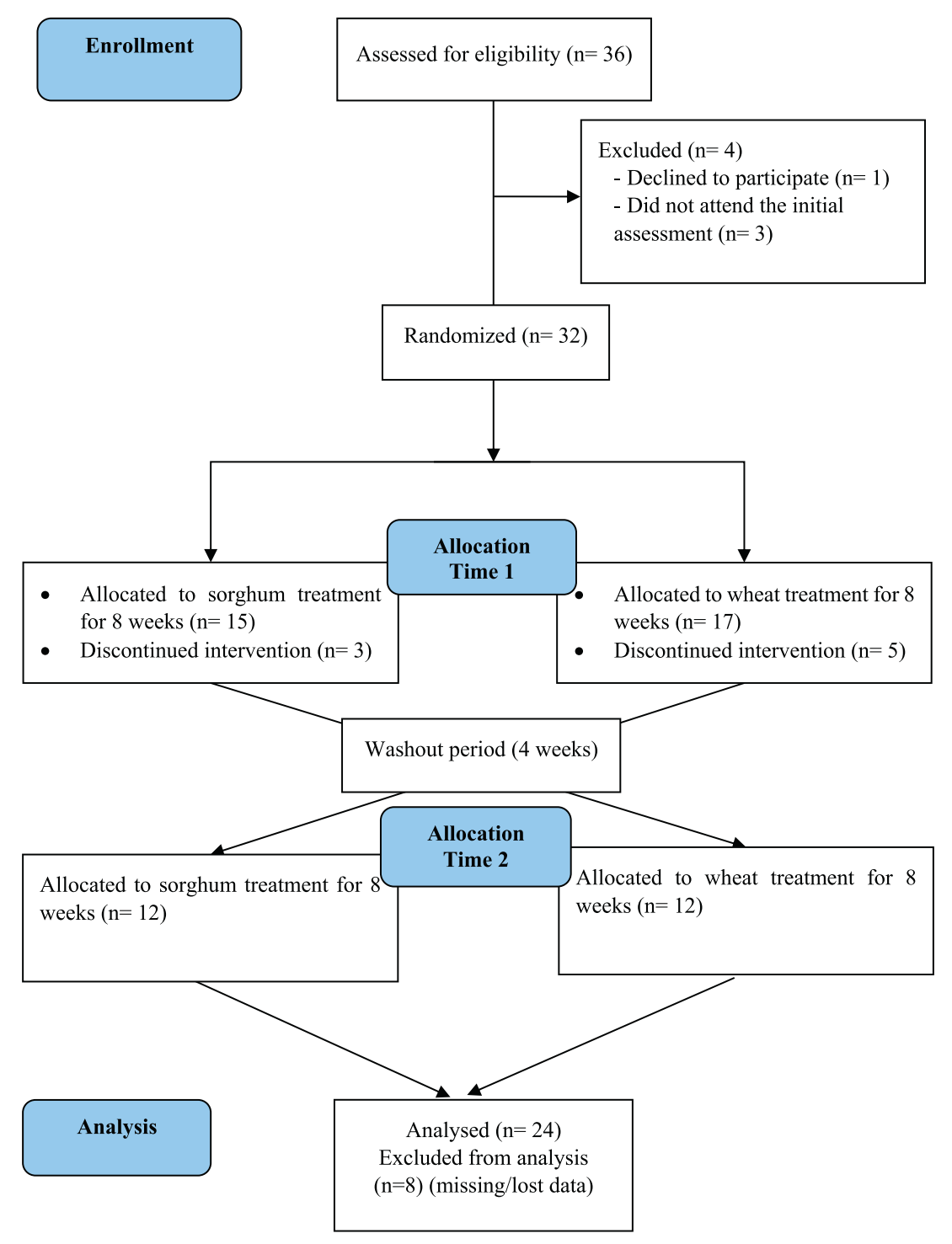

Fig. 1. Screening fluxogram.

in the wheat treatment.

Body fat percentage (BF\%) reduction was higher in the sorghum treatment when compared to the wheat treatment $(-1.90 \pm 1.82 \%$ vs $-0.23 \pm 1.46 \%$ ) (Fig. 2). The test meal with extruded sorghum promoted significative weight loss, decreased WC, waist-to-height ratio and $\mathrm{BF} \%$ (Table 3), but no difference was observed when comparing the two treatments.

Mean daily fat and protein intake did not differ from baseline in both groups. However, there was an increase in carbohydrate $(35.70 \pm 59.79 \mathrm{~g})$, dietary fiber $(5.14 \pm 6.62 \mathrm{~g})$ and energy consumption after sorghum treatment, when compared to wheat treatment (Fig. 2). The increase in carbohydrate consumption positively correlated with dietary fiber consumption $(r=0.650, p=.001)$.

When comparing the two treatments, no difference was observed in biochemical variables, serum vitamins, total antioxidant capacity and glutathione peroxidase (Fig. 3). However, an increase in fasting blood glucose $(3.77 \pm 5.91 \mathrm{mg} / \mathrm{dL})$ was observed after the consumption of extruded wheat. The consumption of extruded sorghum for 8 weeks led to an increase in glutathione peroxidase $(23.75 \pm 41.09 \mathrm{U} / \mathrm{L})$ (Table 4).

\section{Discussion}

This study investigated the potential benefits of chronic consumption of SC319 extruded sorghum (with high content of proanthocyanidins (tannins), 3-DXAs and dietary fiber) on body composition, weight loss, oxidative stress markers and dietary intake in overweight individuals. Extruded sorghum consumption for 8 weeks led to reduction in $\mathrm{BF} \%$ in overweight men when comparing to extruded wheat consumption. In addition to, the body weight, BMI and WC of the participants has reduced after sorghum consumption but no difference was observed when comparing the two treatments.

Wheat consumption did not lead to changes in body weight and body composition. Similar results were also verified in another study, since anthropometric data and body composition in overweight and obese subjects were not affected in response to the consumption of whole-grain wheat during 8 weeks (Vitaglione et al., 2015). However, our results showed that sorghum consumption has a potential to reduce body fat, which plays an important role in the pathogenesis of many chronic diseases. The difference in results between the treatments may be attributed to the bioactive compounds content of sorghum compared to wheat. Therefore, whole grain sorghum may be useful in managing energy balance, favoring overweight control.

Previous studies demonstrated that the consumption of sorghum 
Table 2

Clinical and anthropometric variables and daily consumption of macronutrients of the participants at baseline by treatment.

\begin{tabular}{|c|c|c|}
\hline Variables & Sorghum treatment $(n=24)$ & Wheat treatment $(n=24)$ \\
\hline \multicolumn{3}{|c|}{ Anthropometric variables } \\
\hline Weight (kg) & $90.38 \pm 10.35^{a}$ & $90.19 \pm 10.66^{\mathrm{a}}$ \\
\hline BMI $\left(\mathrm{kg} / \mathrm{m}^{2}\right)$ & $29.07 \pm 1.49^{\mathrm{a}}$ & $29.01 \pm 1.80^{\mathrm{a}}$ \\
\hline $\mathrm{WC}(\mathrm{cm})$ & $99.30 \pm 5.56^{\mathrm{a}}$ & $99.01 \pm 5.92^{\mathrm{a}}$ \\
\hline $\mathrm{SAD}(\mathrm{cm})$ & $21.83 \pm 1.65^{\mathrm{a}}$ & $21.88 \pm 1.54^{\mathrm{a}}$ \\
\hline WHtR & $0.56 \pm 0.03^{\mathrm{a}}$ & $0.57 \pm 0.04^{\mathrm{a}}$ \\
\hline BF (\%) & $32.09 \pm 5.85^{\mathrm{a}}$ & $31.58 \pm 5.39^{\mathrm{a}}$ \\
\hline \multicolumn{3}{|c|}{ Biochemical variables } \\
\hline Glucose (mg/dL) & $87.83 \pm 5.13^{\mathrm{a}}$ & $86.17 \pm 5.71^{\mathrm{a}}$ \\
\hline Insulin $(\mu \mathrm{UI} / \mathrm{mL})$ & $6.31 \pm 2.83^{\mathrm{a}}$ & $6.89 \pm 2.71^{\mathrm{a}}$ \\
\hline HOMA-IR & $1.38 \pm 0.66^{\mathrm{a}}$ & $1.41 \pm 0.66^{\mathrm{a}}$ \\
\hline CRP (mg/L) & $0.51 \pm 1.13^{\mathrm{a}}$ & $0.14 \pm 0.13^{\mathrm{a}}$ \\
\hline TG (mmol/L) & $119.04 \pm 63.60^{\mathrm{a}}$ & $126.21 \pm 61.79^{\mathrm{a}}$ \\
\hline $\mathrm{TC}(\mathrm{mmol} / \mathrm{L})$ & $173.96 \pm 33.31^{\mathrm{a}}$ & $173.87 \pm 29.48^{\mathrm{a}}$ \\
\hline LDL-c (mmol/L) & $106.21 \pm 28.36^{\mathrm{a}}$ & $104.41 \pm 24.63^{\mathrm{a}}$ \\
\hline HDL-c (mmol/L) & $43.92 \pm 6.86^{\mathrm{a}}$ & $44.21 \pm 8.21^{\mathrm{a}}$ \\
\hline \multicolumn{3}{|l|}{ Daily consumption } \\
\hline Energy (kcal) & $1523.83 \pm 187.81^{\mathrm{a}}$ & $1760.32 \pm 350.53^{\mathrm{a}}$ \\
\hline Carbohydrate (g) & $187.71 \pm 46.99^{\mathrm{a}}$ & $232.07 \pm 42.81^{\mathrm{a}}$ \\
\hline Dietary fiber (g) & $14.37 \pm 4.87^{\mathrm{b}}$ & $19.07 \pm 5.26^{\mathrm{a}}$ \\
\hline Fat $(\mathrm{g})$ & $48.24 \pm 10.02^{\mathrm{a}}$ & $52.76 \pm 12.35^{\mathrm{a}}$ \\
\hline Protein (g) & $84.71 \pm 27.13^{\mathrm{a}}$ & $89.31 \pm 28.22^{\mathrm{a}}$ \\
\hline
\end{tabular}

Data are expressed as mean \pm standard deviation. Means followed by different letters differ statistically at $5 \%$ probability by $t$-test. BMI: body mass index, WC: waist circumference, SAD: sagittal abdominal diameter, WHtR: waist-to-height ratio, BF: body fat percentage, HOMA-IR: homeostatic model of assessment of insulin resistance, CRP: high-sensitivity C-reactive protein, TG: triglycerides, TC: total cholesterol, LDL-c: low-density lipoprotein, HDL-c: high-density lipoprotein.
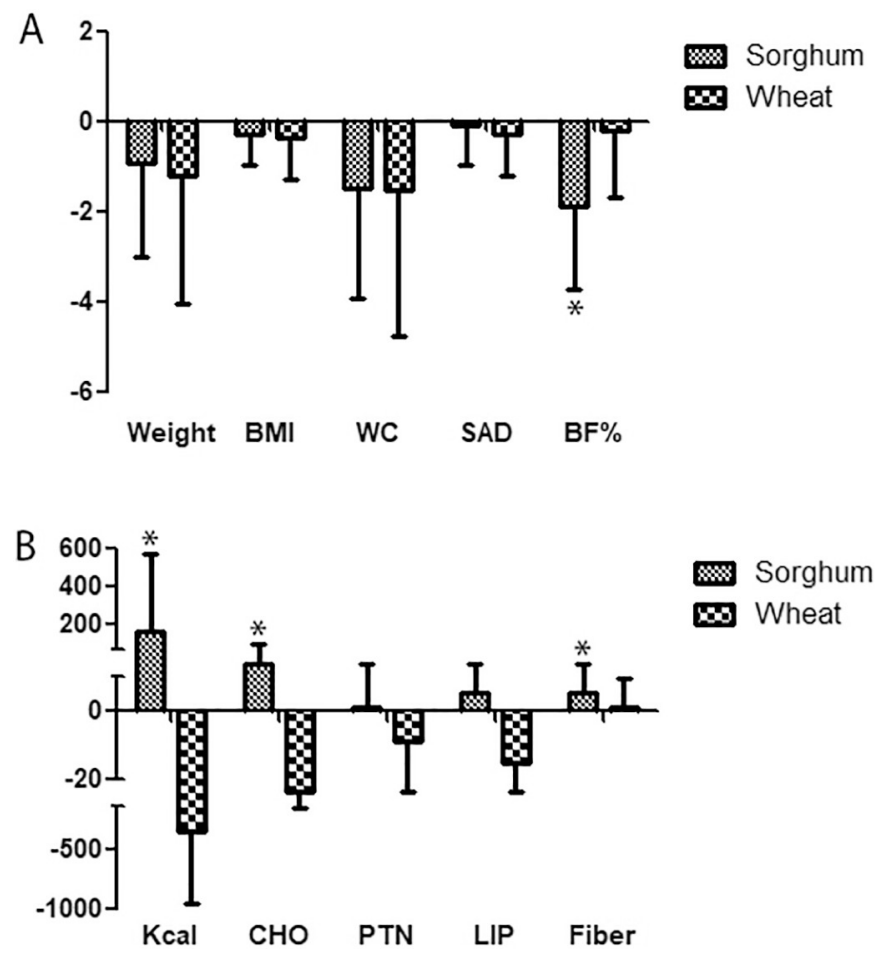

Fig. 2. Evaluation of anthropometric (A) and mean daily consumption of macronutrients (B) in overweight men after intervention. Comparison of the delta values (end values - baseline values); *Means followed by asterisks differed between groups at $5 \%$ probability (Student's $t$-test).

BMI: body mass index; WC: waist circumference; SAD: sagittal abdominal diameter; BF\%: body fat percentage; Kcal: kilocalories; CHO: carbohydrates; PTN: proteins; LIP: lipids. rich in tannins reduces weight gain in animals (rats, pigs, rabbits, and poultry) (Al-Mamary, Molham, Abdulwali, \& Al-Obeidi, 2001; Muriu, Njoka-Njiru, Tuitoek, \& Nanua, 2002). Arbex et al. (2018) verified that extruded sorghum flour consumption reduced the adiposity by reduced fatty acid synthase gene expression in high fat diet-induced obese rats. To our knowledge, to date there are no studies evaluating the effect of chronic consumption of sorghum on weight loss in humans. The reduction in body fat percentage verified in our study may be due to the higher content of dietary fiber, resistant starch and bioactive compounds (especially tannins) of sorghum compared to wheat. The body fat reduction after sorghum consumption may result in part from the complexation of tannins to sorghum starch and protein (Hagerman et al., 1998), by reducing the digestibility of these nutrients energy, thus providing reduction of body weight. Barros et al. (2014) demonstrated that polymeric tannins from sorghum can naturally modify starch by interacting strongly with amylose forming resistant starch. Resistant starch cannot be digested in the small intestine and thus, it reaches the large intestine, delivering the health benefits of dietary fiber. Whole grain sorghum, with high dietary fiber and slowly digestible starches, may increase satiety in humans due, in part, to its effects on the reduction of the glycemic index (GI) of foods (StefoskaNeedham, Beck, Johnson, \& Tapsell, 2015), although we did not observe a reduction in caloric intake in our study. Also, Wee and cols. (Wee, Williams, Gray, \& Horabin, 1999) showed that the consumption of low GI diets favors fat instead of carbohydrate oxidation, leading to body fat reduction, which may have contributed to reduction in $\mathrm{BF} \%$ in our study.

In the present study, waist circumference was reduced in both sorghum and wheat treatments, since both cereals are rich sources of dietary fibers, which shows that sorghum is as beneficial as wheat, being another cereal option for human consumption. The authors of another study also verified reductions in waist circumference of overweight subjects after the consumption of whole-grain wheat and rice during 8 weeks (Kirwan et al., 2016). About 73\% of the subjects reduced WC in our study. Of these, $37.5 \%$ no longer have abdominal obesity. Excess abdominal adiposity is strongly associated with metabolic disturbances such as insulin resistance and hypertriglyceridemia (Despres, 2006). Others authors also observed reduction in waist circumference after whole grains consumption associated with reducedenergy diet in overweight adults (Charlton et al., 2012; Maki et al., 2010).

In the present study, extruded sorghum consumption led to an increase in glutathione peroxidase, which is one of the main enzymatic antioxidants (Lee et al., 2015). However, we have observed no difference when comparing the sorghum treatment with the wheat treatment, which can be attributed to the higher content of bioactive compounds of sorghum compared to wheat. Wheat treatment did not change the glutathione peroxidase. In another study, increased consumption of wheat during 24 weeks also did not modify glutathione peroxidase in men (Wu, Salisbury, Graham, Lyons, \& Fenech, 2009). Cardiovascular risk associated with obesity can be reduced through weight lost which subsequently decreases oxidative stress markers and increased antioxidant system (Bigornia et al., 2010). Superoxide dismutase (SOD), catalase and GPx activities have been found to be inversely related to BMI in obese adults (Mittal \& Kant, 2009). In obese women, serum GPx activity was significantly increased after weight reduction (Bougoulia, Triantos, \& Koliakos, 2006).

Our results suggest that whole grain extruded sorghum consumption can reduce oxidative stress by increasing antioxidant enzymes, such as glutathione peroxidase. In a study (Khan et al., 2015), pasta containing red whole grain sorghum flour enhanced antioxidant status and improved markers of oxidative stress in healthy subjects. This effect may be attributed to its higher content of polyphenols (Khan et al., 2015). Lopes et al. (2018) observed that the oxidative stress was attenuated after the intake of extruded sorghum cereal with a probiotic dairy drink, since there was a reduction in serum malondialdehyde and an 
Table 3

Anthropometric variables of the participants at baseline and endpoint by treatment.

\begin{tabular}{|c|c|c|c|c|}
\hline \multirow[t]{2}{*}{ Variables } & \multicolumn{2}{|c|}{ Sorghum treatment $(n=24)$} & \multicolumn{2}{|c|}{ Wheat treatment $(n=24)$} \\
\hline & Baseline & Endpoint & Baseline & Endpoint \\
\hline Weight (kg) & $90.38 \pm 10.35^{\mathrm{a}}$ & $89.53 \pm 10.99^{b}$ & $90.19 \pm 10.66^{\mathrm{a}}$ & $89.21 \pm 10.96^{\mathrm{a}}$ \\
\hline BMI $\left(\mathrm{kg} / \mathrm{m}^{2}\right)$ & $29.07 \pm 1.49^{\mathrm{a}}$ & $28.79 \pm 1.84^{\mathrm{b}}$ & $29.01 \pm 1.80^{\mathrm{a}}$ & $28.70 \pm 2.13^{\mathrm{a}}$ \\
\hline WC $(\mathrm{cm})$ & $99.30 \pm 5.56^{\mathrm{a}}$ & $97.92 \pm 6.70^{\mathrm{b}}$ & $99.01 \pm 5.92^{\mathrm{a}}$ & $97.58 \pm 6.88^{b}$ \\
\hline $\mathrm{SAD}(\mathrm{cm})$ & $21.83 \pm 1.65^{\mathrm{a}}$ & $21.75 \pm 1.78^{\mathrm{a}}$ & $21.88 \pm 1.54^{\mathrm{a}}$ & $21.59 \pm 2.04^{\mathrm{a}}$ \\
\hline WHtR & $0.56 \pm 0.03^{\mathrm{a}}$ & $0.55 \pm 0.04^{\mathrm{b}}$ & $0.57 \pm 0.04^{\mathrm{a}}$ & $0.56 \pm 0.04 \mathrm{~b}$ \\
\hline $\mathrm{BF}(\%)$ & $32.09 \pm 5.85^{\mathrm{a}}$ & $30.38 \pm 6.23^{b}$ & $31.58 \pm 5.39^{\mathrm{a}}$ & $31.34 \pm 5.57^{\mathrm{a}}$ \\
\hline
\end{tabular}

Data are expressed as mean \pm standard deviation. Means followed by different letters differ statistically at $5 \%$ probability by paired $t$-test or for Wilcoxon matchedpairs signed-rank test, as statistical within group differences (baseline vs. endpoint).

BMI: body mass index, WC: waist circumference, SAD: sagittal abdominal diameter, WHtR: waist-to-height ratio, BF: body fat percentage.
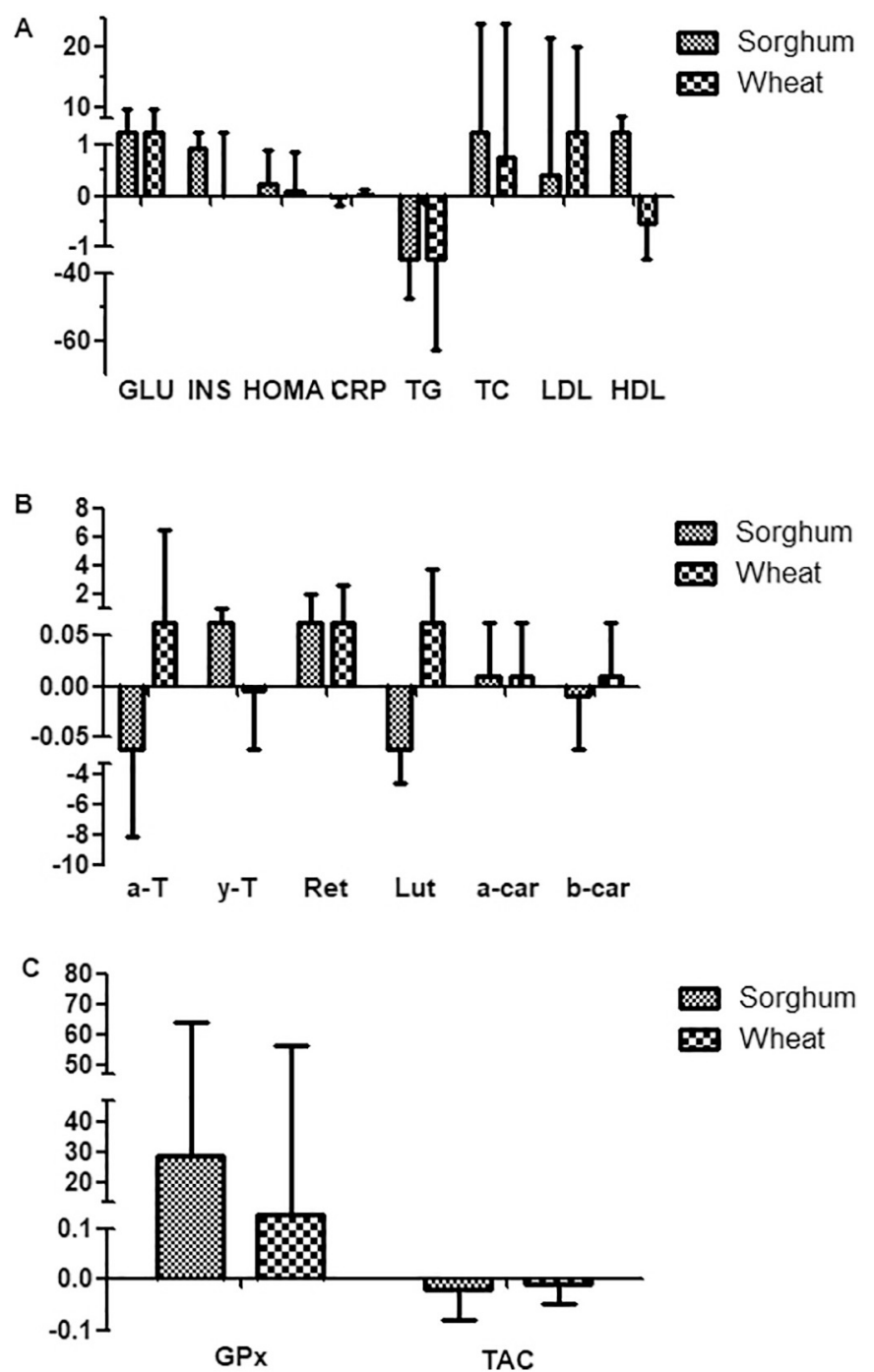

Fig. 3. Evaluation of biochemical variables (A), serum vitamins (B) and oxidative stress markers $(C)$ in overweight men after intervention. Comparison of the delta values (end values - baseline values).

GLU: glucose, INS: insulin, HOMA-IR: homeostatic model of assessment of insulin resistance, CRP: high-sensitivity C-reactive protein, TG: triglycerides, TC: total cholesterol, LDL-c: low-density lipoprotein, HDL-c: high-density lipoprotein, a-T: $\alpha$-tocopherol, y-T: $\gamma$-tocopherol, Ret: retinol, Lut: lutein, a-car: $\alpha$ carotene, b-car: $\beta$-carotene, GPx: Glutathione peroxidase, TAC: total antioxidant capacity. increase in SOD and TAC in individuals with chronic kidney disease. These results may be associated with zinc, dietary fiber, tannins, phenolic compounds, and flavonoids contents in the extruded sorghum cereal (Lopes et al., 2018).

Due to this higher antioxidant activity and phenolic compounds compared to wheat (Anunciação et al., 2017), sorghum consumption has a potential to reduce oxidative stress that plays an important role in the pathogenesis of many chronic diseases such as diabetes, atherosclerosis, some cancers, aging, arthritis, and neurological diseases (Awika \& Rooney, 2004; Stefoska-Needham et al., 2015). The intake of polyphenols compounds can act directly on the inflammatory process, avoiding or decreasing the formation of reactive oxygen species (Cardoso, Pinheiro, Martino, \& Pinheiro-Sant'Ana, 2017).

The consumption of extruded sorghum increased the daily intake of dietary fibers $(\sim 7 \mathrm{~g}$ /day $)$ of the participants. Our results showed that total dietary fiber intake increased to approximately $21 \mathrm{~g} /$ day in sorghum group, which falls within the range of 20 to $35 \mathrm{~g}$ fiber/day recommended by the Institute of Medicine (2005). Lopes et al. (2018) also observed improvements in dietary fiber consumption with extruded sorghum cereal, since a portion of $40 \mathrm{~g}$ is considered a source of fiber, in accordance with Brazilian legislation (ANVISA, 2017). Thus, the inclusion of sorghum in the diet may help meeting nutrition recommendations.

Although dietary fiber intake did not contribute to increased satiety, since no reduction in caloric intake was observed, the synergistic effect of the bioactive compounds of sorghum may have contributed to body fat reduction. Also, the extrusion process reduces high molecular weight proanthocyanidins into low molecular weight compounds, making the food more palatable. In addition, low molecular weight proanthocyanidins are more bioavailable, and can bind to carbohydrates and proteins forming insoluble complexes that are not absorbed by the body, contributing to the meal caloric reduction (Al-Mamary et al., 2001; Cardoso, Pinheiro, de Carvalho, et al., 2015b). Thus, the lower caloric availability in sorghum meal could contribute to the higher caloric intake associated with body weight and body fat reduction observed in the present study. Our results were similar to a study with animals that consumed the same sorghum genotype (de Sousa et al., 2018).

It is noteworthy that in the present study volunteers consumed sorghum once a day, and in a free diet, people can consume $>40 \mathrm{~g}$ of sorghum per day. However, the effects are already unknown and more studies should be conducted.

\section{Conclusion}

Daily consumption of preparations containing $40 \mathrm{~g}$ of sorghum for 8 weeks increased carbohydrate and dietary fiber intake, reduced body fat in overweight men when compared to wheat consumption, and increased the serum glutathione peroxidase concentration inter group. 
Table 4

Antioxidant variables of the participants at baseline and endpoint by treatment.

\begin{tabular}{|c|c|c|c|c|}
\hline \multirow[t]{2}{*}{ Variables } & \multicolumn{2}{|c|}{ Sorghum treatment (test) } & \multicolumn{2}{|c|}{ Wheat treatment (control) } \\
\hline & Baseline & Endpoint & Baseline & Endpoint \\
\hline$\alpha$-tocopherol $(\mu \mathrm{mol} / \mathrm{L})$ & $22.94 \pm 8.04^{\mathrm{a}}$ & $22.60 \pm 6.44^{\mathrm{a}}$ & $22.10 \pm 7.68^{\mathrm{a}}$ & $22.46 \pm 6.49^{\mathrm{a}}$ \\
\hline$\gamma$-tocopherol $(\mu \mathrm{mol} / \mathrm{L})$ & $9.45 \pm 0.89^{\mathrm{a}}$ & $9.62 \pm 0.79^{\mathrm{a}}$ & $9.36 \pm 0.81^{\mathrm{a}}$ & $9.36 \pm 0.61^{\mathrm{a}}$ \\
\hline Retinol $(\mu \mathrm{mol} / \mathrm{L})$ & $4.95 \pm 1.77^{\mathrm{a}}$ & $5.30 \pm 1.19^{\mathrm{a}}$ & $4.94 \pm 1.80^{\mathrm{a}}$ & $5.46 \pm 1.22^{\mathrm{a}}$ \\
\hline Lutein $(\mu \mathrm{mol} / \mathrm{L})$ & $9.19 \pm 8.62^{\mathrm{a}}$ & $8.94 \pm 7.00^{\mathrm{a}}$ & $6.74 \pm 4.53^{\mathrm{a}}$ & $8.57 \pm 9.96^{\mathrm{a}}$ \\
\hline$\alpha$-carotene $(\mu \mathrm{mol} / \mathrm{L})$ & $0.65 \pm 0.29^{\mathrm{a}}$ & $0.63 \pm 0.24^{\mathrm{a}}$ & $0.63 \pm 0.21^{\mathrm{a}}$ & $0.58 \pm 0.16^{\mathrm{a}}$ \\
\hline$\beta$-carotene $(\mu \mathrm{mol} / \mathrm{L})$ & $1.35 \pm 0.59^{\mathrm{a}}$ & $1.23 \pm 0.43^{\mathrm{a}}$ & $1.22 \pm 0.30^{\mathrm{a}}$ & $1.28 \pm 0.52^{\mathrm{a}}$ \\
\hline GPx (U/L) & $102.93 \pm 49.28^{\mathrm{a}}$ & $126.68 \pm 38.70^{b}$ & $99.45 \pm 32.94^{\mathrm{a}}$ & $114.81 \pm 35.82^{\mathrm{a}}$ \\
\hline TAC (mM Trolox) & $0.51 \pm 0.04^{\mathrm{a}}$ & $0.51 \pm 0.04^{\mathrm{a}}$ & $0.54 \pm 0.03^{\mathrm{a}}$ & $0.52 \pm 0.06^{\mathrm{a}}$ \\
\hline
\end{tabular}

$\mathrm{n}=24$ participants in each group. Data are expressed as mean \pm standard deviation. Means followed by different letters differ statistically at $5 \%$ probability by paired $t$-test or for Wilcoxon matched-pairs signed-rank test, as statistical within group differences (baseline vs. endpoint).

GPx: Glutathione peroxidase, TAC: total antioxidant capacity.

Both treatments maintained biochemical markers. Thus, sorghum can be an important strategy for weight loss in humans.

\section{Acknowledgments}

The authors thank the Embrapa Milho e Sorgo (Brazil), Fundação de Amparo à Pesquisa do Estado de Minas Gerais (FAPEMIG, Brazil), Coordenação de Aperfeiçoamento de Pessoal de Ensino Superior (CAPES, Brazil), and Conselho Nacional de Desenvolvimento Científico e Tecnológico (CNPq, Brazil) for granting of financial support for undergraduate research and scholarships.

\section{Conflict of interest}

The authors declare that they have no conflict of interest.

\section{References}

Al-Mamary, M., Molham, A.-H., Abdulwali, A.-A., \& Al-Obeidi, A. (2001). In vivo effects of dietary sorghum tannins on rabbit digestive enzymes and mineral absorption. Nutrition Research, 21(10), 1393-1401.

Anunciação, P. C., Cardoso, L. M., Gomes, J. V. P., Della Lucia, C. M., Carvalho, C. W. P., Galdeano, M. C., ... Pinheiro-Sant'Ana, H. M. (2017). Comparing sorghum and wheat whole grain breakfast cereals: Sensorial acceptance and bioactive compound content. Food Chemistry, 221, 984-989.

Anunciação, P. C., Cardoso, L. M., Queiroz, V. A., de Menezes, C. B., de Carvalho, C. W., Pinheiro-Sant'Ana, H. M., \& Alfenas, R. C. (2018). Consumption of a drink containing extruded sorghum reduces glycaemic response of the subsequent meal. European Journal of Nutrition. 57(1), 251-257.

ANVISA (2017). Alimentos Com Alegações de Propriedades Funcionais e ou de Saúde. Vol. 2018 (Brazil).

Arbex, P. M., de Castro Moreira, M. E., Toledo, R. C. L., de Morais Cardoso, L., PinheiroSant'ana, H. M., dos Anjos Benjamin, L., ... Martino, H. S. D. (2018). Extruded sorghum flour (Sorghum bicolor L.) modulate adiposity and inflammation in high fat dietinduced obese rats. Journal of Functional Foods, 42, 346-355.

Awika, J. M., \& Rooney, L. W. (2004). Sorghum phytochemicals and their potential impact on human health. Phytochemistry, 65(9), 1199-1221.

Barros, F., Awika, J., \& Rooney, L. W. (2014). Effect of molecular weight profile of sorghum proanthocyanidins on resistant starch formation. Journal of the Science of Food and Agriculture, 94(6), 1212-1217.

Bigornia, S. J., Mott, M. M., Hess, D. T., Apovian, C. M., McDonnell, M. E., Duess, M. A., .. Gokce, N. (2010). Long-term successful weight loss improves vascular endothelial function in severely obese individuals. Obesity, 18(4), 754-759.

Bougoulia, M., Triantos, A., \& Koliakos, G. (2006). Plasma interleukin-6 levels, glutathione peroxidase and isoprostane in obese women before and after weight loss. Association with cardiovascular risk factors. HORMONES-ATHENS, 5(3), 192.

Cardoso, L.d. M., Pinheiro, S. S., da Silva, L. L., de Menezes, C. B., de Carvalho, C. W. P., Tardin, F. D., ... Pinheiro-Sant'Ana, H. M. (2015a). Tocochromanols and carotenoids in sorghum (Sorghum bicolor L.): Diversity and stability to the heat treatment. Food Chemistry, 172, 900-908.

Cardoso, L.d. M., Pinheiro, S. S., de Carvalho, C. W. P., Queiroz, V. A. V., de Menezes, C. B., Moreira, A. V. B., ... Pinheiro-Sant'Ana, H. M. (2015b). Phenolic compounds profile in sorghum processed by extrusion cooking and dry heat in a conventional oven. Journal of Cereal Science, 65, 220-226.

Cardoso, L.d. M., Pinheiro, S. S., Martino, H. S. D., \& Pinheiro-Sant'Ana, H. M. (2017). Sorghum (Sorghum bicolor L.): Nutrients, bioactive compounds, and potential impact on human health. Critical Reviews in Food Science and Nutrition, 57(2), 372-390.

Charlton, K. E., Tapsell, L. C., Batterham, M. J., O'Shea, J., Thorne, R., Beck, E., \& Tosh, S.
M. (2012). Effect of 6 weeks' consumption of $\beta$-glucan-rich oat products on cholesterol levels in mildly hypercholesterolaemic overweight adults. British Journal of Nutrition, 107(07), 1037-1047.

Chávez, D. W. H., Ascheri, J. L. R., Carvalho, C. W. P., Godoy, R. L. O., \& Pacheco, S. (2017). Sorghum and roasted coffee blends as a novel extruded product: Bioactive compounds and antioxidant capacity. Journal of Functional Foods, 29, 93-103.

Ciacci, C., Maiuri, L., Caporaso, N., Bucci, C., Del Giudice, L., Massardo, D. R., ... Ioerger, B. (2007). Celiac disease: In vitro and in vivo safety and palatability of wheat-free sorghum food products. Clinical Nutrition, 26(6), 799-805.

Despres, J. (2006). Intra-abdominal obesity: An untreated risk factor for Type 2 diabetes and cardiovascular disease. Journal of Endocrinological Investigation, 29(3), 77.

Dykes, L., \& Rooney, L. W. (2006). Sorghum and millet phenols and antioxidants. Journal of Cereal Science, 44(3), 236-251.

Erciyas, F., Taneli, F., Arslan, B., \& Uslu, Y. (2004). Glycemic control, oxidative stress, and lipid profile in children with type 1 diabetes mellitus. Archives of Medical Research, 35(2), 134-140.

Farrar, J. L., Hartle, D. K., Hargrove, J. L., \& Greenspan, P. (2008). A novel nutraceutical property of select sorghum (Sorghum bicolor) brans: Inhibition of protein glycation. Phytotherapy Research, 22(8), 1052-1056.

Friedewald, W. T., Levy, R. I., \& Fredrickson, D. S. (1972). Estimation of the concentration of low-density lipoprotein cholesterol in plasma, without use of the preparative ultracentrifuge. Clinical Chemistry, 18(6), 499-502.

Hagerman, A. E., Riedl, K. M., Jones, G. A., Sovik, K. N., Ritchard, N. T., Hartzfeld, P. W., \& Riechel, T. L. (1998). High molecular weight plant polyphenolics (tannins) as biological antioxidants. Journal of Agricultural and Food Chemistry, 46(5), 1887-1892.

Institute of Medicine (2005). Dietary reference intakes for energy, carbohydrate, fiber, fat, fatty acids, cholesterol, protein and amino acids. Washington, DC: National Academies Press.

Jellife, D. B. (1966). The assessment of the nutritional status of the community (with special reference to field surveys in developing regions of the world). Monograph Series. World Health Organization, 3, 256-271.

Khan, I., Yousif, A. M., Johnson, S. K., \& Gamlath, S. (2015). Acute effect of sorghum flour-containing pasta on plasma total polyphenols, antioxidant capacity and oxidative stress markers in healthy subjects: A randomised controlled trial. Clinical Nutrition, 34(3), 415-421.

Kirwan, J. P., Malin, S. K., Scelsi, A. R., Kullman, E. L., Navaneethan, S. D., Pagadala, M. R., ... Kochhar, S. (2016). A whole-grain diet reduces cardiovascular risk factors in overweight and obese adults: A randomized controlled trial. The Journal of Nutrition, 146(11), 2244-2251.

Lee, Y.-M., Han, S.-I., Song, B. C., \& Yeum, K.-J. (2015). Bioactives in commonly consumed cereal grains: Implications for oxidative stress and inflammation. Journal of Medicinal Food, 18(11), 1179-1186.

Lopes, R. D. C. S. O., de Lima, S. L. S., da Silva, B. P., Toledo, R. C. L., de Castro Moreira, M. E., Anunciação, P. C., ... Ribeiro, A. Q. (2018). Evaluation of the health benefits of consumption of extruded tannin sorghum with unfermented probiotic milk in individuals with chronic kidney disease. Food Research International.

Maki, K. C., Beiseigel, J. M., Jonnalagadda, S. S., Gugger, C. K., Reeves, M. S., Farmer, M. V., ... Rains, T. M. (2010). Whole-grain ready-to-eat oat cereal, as part of a dietary program for weight loss, reduces low-density lipoprotein cholesterol in adults with overweight and obesity more than a dietary program including low-fiber control foods. Journal of the American Dietetic Association, 110(2), 205-214.

Matsuda, M., \& Shimomura, I. (2013). Increased oxidative stress in obesity: Implications for metabolic syndrome, diabetes, hypertension, dyslipidemia, atherosclerosis, and cancer. Obesity Research \& Clinical Practice, 7(5), e330-e341.

Mera, R., Thompson, H., \& Prasad, C. (1998). How to calculate sample size for an experiment: A case-based description. Nutritional Neuroscience, 1(1), 87-91.

Mittal, P. C., \& Kant, R. (2009). Correlation of increased oxidative stress to body weight in disease-free post menopausal women. Clinical Biochemistry, 42(10-11), 1007-1011.

Monteiro, J. P. (2007). Consumo alimentar. Rio de Janeiro: Visualizando porções.

Moraes, É. A., Natal, D. I. G., Queiroz, V. A. V., Schaffert, R. E., Cecon, P. R., de Paula, S. O., ... Martino, H. S. D. (2012). Sorghum genotype may reduce low-grade inflammatory response and oxidative stress and maintains jejunum morphology of rats fed a hyperlipidic diet. Food Research International, 49(1), 553-559.

Moraes, É. A., de Silva Marineli, R., Lenquiste, S. A., Queiroz, V. A. V., Camargo, R. L., 
Borck, P. C., Carneiro, E. M., \& Júnior, M. R. M. (2018). Whole sorghum flour improves glucose tolerance, insulin resistance and preserved pancreatic islets function in obesity diet-induced rats. Journal of Functional Foods. 45, 530-540.

Muriu, J., Njoka-Njiru, E., Tuitoek, J., \& Nanua, J. (2002). Evaluation of sorghum (Sorghum bicolor) as replacent for maize in the diet of growing rabbits (Oryctolagus cuniculus). Asian Australasian Journal of Animal Sciences, 15(4), 565-569.

Pickering, T. G., Hall, J. E., Appel, L. J., Falkner, B. E., Graves, J., Hill, M. N., ... Roccella, E. J. (2005). Recommendations for blood pressure measurement in humans and experimental animals part 1: Blood pressure measurement in humans: A statement for professionals from the Subcommittee of Professional and Public Education of the American Heart Association Council on High Blood Pressure Research. Hypertension, 45(1), 142-161.

Pontieri, P., Mamone, G., De Caro, S., Tuinstra, M. R., Roemer, E., Okot, J., ... Pignone, D. (2013). Sorghum, a healthy and gluten-free food for celiac patients as demonstrated by genome, biochemical, and immunochemical analyses. Journal of Agricultural and Food Chemistry, 61(10), 2565-2571.

Sociedad Espanola para el Estudio de la Obesidad (2000). SEEDO'2000 Consensus for the evaluation of overweight and obesity and the establishment of criteria for therapeutic intervention. Medicina Clínica (Barcelona), 115(15), 587-597.

de Sousa, A. R., de Castro Moreira, M. E., Toledo, R. C. L., dos Anjos Benjamin, L Queiroz, V. A. V., Veloso, M. P., ... Martino, H. S. D. (2018). Extruded sorghum (Sorghum bicolor L.) reduces metabolic risk of hepatic steatosis in obese rats consuming a high fat diet. Food Research International.

Stefoska-Needham, A., Beck, E. J., Johnson, S. K., \& Tapsell, L. C. (2015). Sorghum: An underutilized cereal whole grain with the potential to assist in the prevention of chronic disease. Food Reviews International, 31(4), 401-437.
Taylor, J. R., Belton, P. S., Beta, T., \& Duodu, K. G. (2014). Increasing the utilisation of sorghum, millets and pseudocereals: Developments in the science of their phenolic phytochemicals, biofortification and protein functionality. Journal of Cereal Science, 59(3), 257-275.

Turner, T., \& Burri, B. J. (2012). Rapid isocratic HPLC method and sample extraction procedures for measuring carotenoid, retinoid, and tocopherol concentrations in human blood and breast milk for intervention studies. Chromatographia, 75(5), 241-252.

Vitaglione, P., Mennella, I., Ferracane, R., Rivellese, A. A., Giacco, R., Ercolini, D., .. Fogliano, V. (2015). Whole-grain wheat consumption reduces inflammation in a randomized controlled trial on overweight and obese subjects with unhealthy dietary and lifestyle behaviors: Role of polyphenols bound to cereal dietary fiber. The American Journal of Clinical Nutrition, 101(2), 251-261.

Wee, S.-L., Williams, C., Gray, S., \& Horabin, J. (1999). Influence of high and low glycemic index meals on endurance running capacity. Medicine and Science in Sports and Exercise, 31(3), 393-399.

World Health Organization (2000). Obesity: Preventing and managing the global epidemic. World Health Organization.

World Health Organization. (2016). Obesity and overweight.

Wu, J., Salisbury, C., Graham, R., Lyons, G., \& Fenech, M. (2009). Increased consumption of wheat biofortified with selenium does not modify biomarkers of cancer risk, oxidative stress, or immune function in healthy Australian males. Environmental and Molecular Mutagenesis, 50(6), 489-501.

Yang, L., Browning, J., \& Awika, J. (2009). Sorghum 3-deoxyanthocyanins possess strong phase II enzyme inducer activity and cancer cell growth inhibition properties. Journal of Agricultural and Food Chemistry, 57(5), 1797-1804. 